Cad. Líng. Lit. Hebr., n. 15, p. 232-249, 2017

\title{
O LIVRO DE ESTER E A IRREVOGABILIDADE DAS LEIS AQUEMÊNIDAS
}

\section{THE BOOK OF ESTHER AND THE IRREVOCABILITY OF ACHAEMENID LAWS}

\author{
Matheus Treuk Medeiros de Araujo*
}

\section{Resumo}

Uma objeção frequentemente apresentada contra a historicidade do livro bíblico de Ester é sua referência à "irrevogabilidade" das leis persas. Mesmo recentemente, alguns comentadores recusaram a verossimilhança de tal noção, asseverando que ela seria impraticável. No entanto, o estudo do sistema jurídico e judicial da Pérsia Aquemênida pode fornecer informações valiosas a respeito de como interpretar certas passagens de Ester.

Palavras-chave: Ester, Pérsia, Direito.

\begin{abstract}
One objection usually raised against the historicity of the biblical book of Esther is its reference to the "irrevocability" of Persian statutory laws. Even recently, some commentators have denied the likelihood of such an idea due to its alleged impracticability. However, the study of Achaemenid Persia legal and judicial systems may provide valuable information concerning the most fitting way to interpret some passages of Esther.
\end{abstract}

\footnotetext{
* Doutorando em História Social pela Universidade de São Paulo. Pesquisador do Laboratório do Antigo Oriente Próximo. Bolsista regular da Fundação de Amparo à Pesquisa do Estado de São Paulo (FAPESP - Processo n. ${ }^{\circ}$ 2016/14318-0) com estágio doutoral na École Française de Rome sob financiamento da Coordenação de Aperfeiçoamento de Pessoal de Nível Superior (CAPES - Processo n. ${ }^{\circ} 88881.135183 / 2016-01$ ).
} 
Keywords: Esther, Persia, Law.

Conta a Bíblia hebraica que o monarca Assuero, senhor da Pérsia e de outros tantos reinos, promovera, no terceiro ano de seu reinado, um fabuloso banquete a seus oficiais e súditos, com o propósito de revelar-lhes a magnitude de sua glória imperial ${ }^{1}$. Passados 180 dias, durante os quais o rei e seus convidados teriam aproveitado prodigamente o festim, Assuero realizou ainda outro banquete, igualmente luxuoso, destinado a todo o povo que se encontrava na fortaleza de Susa².

Regada a muito vinho, a festa não acabou bem. No sétimo dia, Assuero, bastante embriagado, desejara, à moda de um Candaules $^{3}$, revelar a beleza da esposa aos súditos e oficiais, contrariando a aversão próximo-oriental à exposição do corpo feminino. Instada a comparecer e se submeter ao escrutínio do ávido público, a rainha Vasti optou por desobedecer ao rei. Este, por sua vez, seguiu o conselho de sete sábios e puniu a empáfia com a destituição de Vasti e sua exclusão do convívio real. A decisão, inscrita nas "leis da Pérsia e da Média” e tornada “irrevogável”, foi publicada em todo o império, por razões pedagógicas 4 .

Sem Vasti, o rei da Pérsia foi forçado a encontrar outra esposa para ocupar seu lugar. Coube a Hadassa, ou Ester, o papel de consorte do rei. Ester era uma jovem judia muito bela, adotada como filha por certo Mardoqueu, seu primo, quem, ao que tudo indica, exercia algum tipo de serviço no palácio ${ }^{5}$. Nessa posição, aliás, o primo de Ester fora capaz de denunciar e impedir que se consumasse uma conspiração contra o rei, feito digno de registro nas crônicas reais 6.

\footnotetext{
${ }^{1}$ Cf. ESTER, 1:1-4.

${ }^{2}$ Cf. ESTER, 1:5-8.

${ }^{3}$ HERÓDOTO 1.8-13. Cf. também LEWELLYN-JONES, 2013, p. 104.

${ }^{4}$ Cf. ESTER, 1:9-22.

${ }^{5} \mathrm{Cf}$. ESTER, 2:1-21.

${ }^{6} \mathrm{Cf}$. ESTER, 2:23.
} 
Cad. Líng. Lit. Hebr., n. 15, p. 232-249, 2017

Havia no reino também certo Amã, membro da corte elevado à condição de oficial supremo, que desprezava o judeu Mardoqueu, resistente, por profissão de fé, a prestar-lhe sinais de obediência e submissão ${ }^{7}$. Por esse motivo, Amã maquinara o extermínio de Mardoqueu e de todo o seu povo, convencendo Assuero a prolatar a decisão de destruir os judeus no dia 13 de Adar ${ }^{8}$.

Ora, a rainha Ester logo teve ciência do luto de Mardoqueu e de todo o povo judeu pela sua desgraçada sorte. Desejando interceder por seu povo, ela solicitou a Mardoqueu e aos judeus de Susa que por ela jejuassem, enquanto ela própria arriscava a vida ao adentrar, sem permissão, o vestíbulo interior do palácio, onde se encontrava o rei ${ }^{9}$. Este, encantado pela graça de Ester, disse-lhe que atenderia a qualquer pedido seu, ao que a rainha respondeu convidando Assuero e Amã para um jantar ${ }^{10}$.

$\mathrm{Na}$ noite anterior ao jantar, o rei, insone, solicitou que lhe fosse recitado seu livro de crônicas, do qual constava o feito do judeu Mardoqueu para salvá-lo de alguns eunucos conspiradores. Ironicamente, enquanto o vilão Amã maquinava para exigir do rei que o insubordinado Mardoqueu fosse imediatamente enforcado, Assuero decidira-se distinguir seu esquecido salvador com sinais de respeito. Para o absoluto desgosto de Amã, o rei então lhe pediu que conduzisse Mardoqueu a cavalo pela praça da cidade e o cumulasse de honras ${ }^{11}$.

A desgraça de Amã seria ainda maior. Quando o rei e seu oficial sentaram-se à mesa com Ester, a rainha pediu clemência para com seu povo e acusou Amã de perseguir os judeus. O rei, convicto de que Amã também tentara violentar a rainha, ordenou que o enforcassem exatamente na estrutura preparada contra Mardoqueu ${ }^{12}$. Por outro lado, incapaz de revogar

\footnotetext{
${ }^{7}$ Cf. ESTER, 3:1-6

${ }^{8}$ Cf. ESTER, 3:7-13.

${ }^{9} \mathrm{Cf}$. ESTER, 4:1-17.

${ }^{10} \mathrm{Cf}$. ESTER, 5:1-8.

${ }^{11}$ Cf. ESTER, 6:1-13.

${ }^{12} \mathrm{Cf}$. ESTER, 7.
} 
sua decisão inicial de extermínio, tida como “irrevogável”, o rei concedeu aos judeus o direito de se defenderem e matarem seus inimigos ${ }^{13}$.

No dia agendado para sua destruição, os judeus, amparados por decisão real e salvos pela intercessão de Ester, levaram a melhor. Os dias 14 e 15 de Adar, por conseguinte, se tornaram datas de jubilosa celebração, a chamada festa de Purim ${ }^{14}$, enquanto a fama de Ester e Mardoqueu se eternizaria na memória.

Despida de seus elementos romanceados, a narrativa acima apresenta descrições históricas e uma sequência factual que foram, desde muito cedo, objeto de calorosos debates acadêmicos. Ambientada no Império Persa Aquemênida, a história contada pelo autor de Ester $^{15}$ faz referência a certo rei "Assuero", identificado pelos especialistas como o Xerxes I (486-465 a.C.) das fontes gregas e iranianas. Na região oeste do Irã, onde se situam as históricas províncias de Kermanshah, Khuzistão e Lorestão, encontram-se não só a Susa mencionada pela Bíblia, capital do antigo Império Aquemênida, mas também Hamadã, onde há um mausoléu tradicionalmente associado à rainha Ester e ao seu primo ${ }^{16}$. As menções aos sete conselheiros do rei, à extensão do império, às maneiras da corte e aos suntuosos palácios da realeza são todos fatos atestados e que dão uma coloração histórica à narrativa de Ester (BAYLES, 2013, p. 65).

Apesar disso, muitos comentaristas, desde ao menos Lewis Bayles Paton, em 1908, insistiram no caráter ficto e fantástico da narrativa de Ester. Bayles, seguido por Carey A. Moore e, mais recentemente, Jon D. Levenson, levantaram uma série de problemas que constituiriam óbice ao reconhecimento da historicidade da obra. A questão foi sintetizada por

\footnotetext{
${ }^{13}$ Cf. ESTER, 8:7-12.

${ }^{14}$ Cf. ESTER, 8:16-22.

${ }^{15} \mathrm{O}$ "autor" ou redator é uma ficção para uma pluralidade de autores. Cf. FOX, 2001, p. 254-273.

${ }^{16}$ A atribuição é provavelmente equivocada. Cf. MATHESON, 1976, p. 110-111.
} 
Cad. Líng. Lit. Hebr., n. 15, p. 232-249, 2017

Adele Berlin, em artigo que avança uma hipótese heterodoxa quanto à intenção do autor e à recepção do livro de Ester. In verbis:

Pouquíssimos estudiosos da Bíblia do século XX acreditavam na historicidade do livro de Ester, mas, ainda assim, eles certamente despenderam enormes esforços para justificar sua posição. Lewis Bayles Paton, em 1908, escreveu 14 páginas resumindo argumentos favoráveis e contrários à sua historicidade, concluindo que o livro não era histórico. Em 1971, Carey A. Moore dedicou 11 páginas ao tema e chegou à mesma conclusão. Em comentários mais recentes, os de Michael V. Fox em 1991 e Jon D. Levenson em 1997, encontramos nove e cinco páginas respectivamente, ambos os autores concordando que $\mathrm{o}$ livro é ficcional. (BERLIN, 2001, p. 3, [tradução nossa])

Dentre os problemas apontados pelos críticos, encontram-se, recorrentemente, a ausência de referências históricas às rainhas Ester e Vasti (e, para ser preciso, à nomeação de outra rainha para o período nas fontes gregas), a menção a 127 províncias do Império Aquemênida e a reiterada noção da irrevogabilidade da assim chamada "lei dos persas e dos medos". As questões foram assim formuladas por Carey Moore (1971, p. 71-72; p. 4, [tradução nossa]):

Algumas das afirmações desse livro são contrariadas pelos historiadores gregos. Por exemplo, durante o período entre o $7^{\circ}$ e $12^{\circ}$ anos do reinado de Xerxes, sua esposa não era Ester, mas Améstris (Heródoto, vii. 114; ix. 112). [...] De acordo com 1:1 e 8:9, o Império Persa era dividido em 127 satrapias, mas Heródoto iii.80 informa apenas 20, e as inscrições aquemênidas nomeiam não mais que 27. [...] A alegação de que as leis dos persas e dos medos não poderiam ser alteradas $(1: 19,8: 8)$, que também aparece no livro tardio de Daniel (6:8-9), não é confirmada por qualquer evidência antiga. [...]

Medînôt são províncias (ver também Neemias i.3, vii, 6; Esdras ii.1), não satrapias; $O$ Império Persa nunca teve mais do que 31 satrapias [...]. Apesar de especulações acadêmicas, não há explicação satisfatória para o número específico de províncias aqui indicado.

Levenson (1997, p. 24-25, [tradução nossa]), de maneira similar, assevera:

Sabemos que a esposa de Xerxes se chamava Améstris (7:114; 9:112). [...] Não há evidência para a existência de 127 províncias ou satrapias $(1: 1,8: 9)$. [ ...] Ou, para dar outro exemplo, a noção, acentuada em Ester $(1: 19,8: 8)$ e igualmente em Daniel $(6: 9,13$, 16) de que a lei dos persas e dos medos seria irrevogável não possui corroboração externa e pareceria absolutamente impraticável. 
E, igualmente, Fox (2001, p. 22, [tradução nossa]):

A noção de que os persas e os medos não poderiam derrogar suas próprias leis, até mesmo decretos ad hoc, é uma pressuposição básica do livro de Ester. Além de Ester, ela é encontrável apenas em Daniel $(6: 8,12$ e 15). Ela não é atestada pelas fontes gregas e persas e parece uma regra impossível para o governo de um império.

Outros autores, de corrente hoje minoritária, adotaram uma postura mais tradicional, defendendo a fiabilidade da narrativa de Ester, ao menos em contornos gerais (YAMAUCHI, 1996). Assim, para citar apenas um exemplo, William Shea contestou a refutação do caráter histórico de Ester a partir da menção a 127 "satrapias", uma vez que a palavra medînôt não denotaria satrapias, mas províncias do império, isto é, circunscrições administrativas de menor nível hierárquico (SHEA, 1976, p. 245). O argumento de Shea, diga-se de passagem, é muito razoável (FOX, 2001, p. 15), encontrando respaldo não apenas no próprio livro de Ester, que diferencia, direta ou indiretamente, esses dois graus hierárquicos da administração aquemênida $(8.9,9.3)$, mas também no livro de Esdras (5:8) e em documentos administrativos do Império Persa que empregam a palavra com esse sentido (BRIANT, 2002, p. 195). É fácil ver, ademais, como os argumentos de Levenson e Moore reproduzem, de maneira mais sofisticada, um comentário originalmente incorreto de Paton, que efetivamente equiparava medînot a satrapias (PATON, 1908, p. 72).

Apesar das vozes dissonantes, a disputa acerca da irrevogabilidade das leis persas, em particular, é uma questão que continua a suscitar dificuldades. Considerada "impraticável” por Levenson e “impossível” por Fox, ela ainda é tida como uma invenção com propósitos meramente literários. A corrente que nega sua verossimilhança é tão antiga que podemos encontrar suas sementes em Jean Bodin (1579, p. 102), para quem a regra seria uma mentira contada por personagens do livro de Daniel. 
Cad. Líng. Lit. Hebr., n. 15, p. 232-249, 2017

Seja como for, a noção da irrevogabilidade é tema central da narrativa de Ester, onde encontramos duas referências explícitas (Ester 1.19 e Ester 8:8). No primeiro caso, diz-se que a deposição da rainha Vasti deveria ser inscrita "nas leis" (בְִּ no no texto massorético ou, na

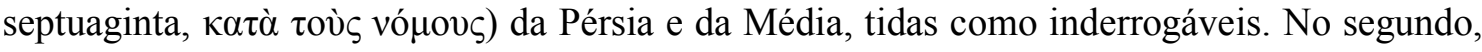
a referência é a uma decisão real endereçada aos judeus, "irrevogável” após sua formalização. Pois bem, seria tal construção um artifício puramente literário, visando conferir à narrativa os fundamentos do conflito esperado em qualquer trama? O estudo específico do direito aquemênida pode nos dar algumas pistas. ${ }^{17}$

Aceitando a hipótese de uma continuidade básica entre as culturas jurídicas de diferentes sociedades próximo-orientais no tempo e no espaço, podemos dizer que o direito aquemênida, à semelhança do direito paleo-babilônico ou assírio, era fundamentalmente costumeiro. Em outras palavras, a "fonte do direito" mais importante das antigas sociedades orientais era, ao contrário do que se poderia imaginar, o costume. A lei, com o sentido de direito positivo, parece uma inovação tardia. No antigo Oriente Próximo, a figura que dela mais se aproxima é o decreto real(WELLS, 2005, p. 184).

No que diz respeito às fontes do direito mesopotâmico, o emblemático caso do “Código" de Hamurabi é frequente fonte de equívocos. Descoberta em Susa, em 1902, a estela contendo tal texto foi tida por muito tempo como um dos primeiros documentos legais de natureza prescritiva da história da humanidade. Jean-Vincent Scheil, o epigrafista que elaborou uma versão pioneira do texto, classificou-o como “código" (BOUZON, 2002, p. 12). No entanto, o exame cuidadoso das inscrições, inclusive à luz de outros documentos jurídicos da Babilônia antiga, conduz à hipótese de que esse documento não seria um código, no sentido moderno do termo, contendo disposições vinculantes do direito positivo.

${ }^{17}$ Uma descrição geral da mecânica institucional aquemênida, com breve esboço da hipótese ora explorada, foi empreendida primeiramente em ARAUJO, 2016, p. 22-25. 
Os motivos para reavaliar a natureza jurídica da estela de Hamurabi são muitos. Ao contrário dos códigos modernos, as leis de Hamurabi não são exaustivas e universais, compreendendo um levantamento sistemático de todas as regras legais do reino (BOTTÉRO, 1987, p. 303). O código é casuístico, pressupõe prévio conhecimento jurídico por parte de sua audiência e aborda situações que dificilmente ocorreriam na prática (WELLS, 2005, p. 185). Em outras palavras, o "código", assim como outros documentos similares da Mesopotâmia, não corresponderia ao nosso direito positivo (WELLS, 2005, p. 185). Ele seria, possivelmente, uma combinação de propaganda, jurisprudência (decisões para casos reais) e desenvolvimentos teóricos de finalidade pedagógica (SLANSKI, 2013, p. 103).

À semelhança de seus antecessores orientais, o Império Persa Aquemênida, único em extensão territorial e diversidade étnica, não parece ter sido regido por normas de direito positivo. Ao contrário do que sugeriu Olmstead (1948, p. xiv), não há evidência de um código imperial regulando todo o território submetido à autoridade do rei dos reis. No máximo, poderíamos falar de alguns princípios e regulações fiscais de amplo alcance. As normas vigentes na periferia do império eram, na verdade, as normas de cada povo, às quais, muito provavelmente, era conferida validade por um ato de "autorização real" (FREI, 2001, p. 7). Os casos de Judá e do Egito são emblemáticos: o autor de Esdras identifica a lei de seu Deus à lei do rei persa ${ }^{17}$, enquanto outro documento antigo relata o empreendimento de Dario I para compilar o direito egípcio do período saíta (BRIANT, 2002, p. 490).

Havia, sim, um vigoroso e avançado sistema judicial na província da Babilônia, onde a evidência de direito aplicado é substancial. Os tribunais locais, de natureza inquisitiva, resolviam litígios conforme os costumes e dentro de limites de competência razoavelmente bem definidos. Os monarcas orientais emitiam decisões para casos específicos ou como

${ }^{17}$ Cf. ESDRAS, 7.26. 
Cad. Líng. Lit. Hebr., n. 15, p. 232-249, 2017

representantes do grau máximo da justiça terreal (BUCCI, 1983), uma espécie de último grau recursal do sistema, como explicam Dandamaev e Lukonin (2004, p. 117, [tradução nossa]):

Os persas tinham seu próprio direito primitivo com base nos costumes. As decisões do rei eram o tribunal de último grau recursal e não estavam sujeitas a alterações, mas o rei era obrigado a governar em conformidade com as práticas tradicionais dos persas e tinha que buscar conselho com os representantes dos sete principais clãs da aristocracia, que cumpriam um papel central na vida jurídica do país.

No período neobabilônico e aquemênida, as decisões reais serviam, ademais, como importante fonte de orientação dos juízes da Babilônia, como assevera Holz (2014, p. 8, tradução nossa):

A evidência da própria prática do direito confirma as atividades jurídicas e legislativas do rei [...]. Alguns textos registram como os oficiais dos templos consultavam o registro escrito das decisões dos reis, até mesmo, possivelmente, o código de leis do próprio soberano. Várias apelações, inclusive algumas desta antologia, demonstram a evolução de casos da jurisdição local das autoridades em Eanna ao julgamento pelos juízes reais e até mesmo ao tribunal do rei na Babilônia.

O termo usado pelo autor de Ester para se referir às chamadas "leis" dos persas e medos se origina do persa antigo dāta (Ester 1.19). Pierre Briant, especialista de renome, expressa reservas quanto à tradução de dāta por "direito", em particular devido às confusões causadas pela polissemia da palavra moderna. Defende, por outro lado, que o termo denotaria, em geral, os costumes, tendo também, em algumas ocorrências específicas, o significado de regulações fiscais do império(BRIANT, 2002, p. 510).

Nas inscrições reais aquemênidas, dāta aparece tanto com o sentido de regras impostas pela autoridade real (DB $\S 8, \mathrm{DNa} \S 3, \mathrm{DSE} \S 3-4, \mathrm{XPh} \S 3)$ quanto com o sentido de lei divina (XPh §7) (LECOQ, 1997, p. 167). Para Briant, o termo, na famosa inscrição de Behistun (DB §8), não passaria de uma referência ao dever de lealdade dos súditos e às regras imperiais de natureza fiscal, isto é, a obrigação de pagar tributos (BRIANT, 2002, p. 511). Em documentos 
da Babilônia aquemênida, é atestada igualmente a expressão dātu ša šarri, "lei do rei”, que, segundo Briant, também denotaria (precipuamente) regulações fiscais. Sobre a ocorrência do termo no livro de Ester, assim se expressa Briant (2002, p. 510, tradução nossa):

No livro de Ester, o termo data é empregado 19 vezes, para definir um regulamento áulico (por exemplo, 1.8: vinho reservado ao rei kata prokeimenon nomon) ou para fazer referência aos costumes estabelecidos (1.15 julgamento de Ester [sic] kata ton nomon) em função dos quais o rei emite um decreto (1.19: prostagma).

Mas o termo também tem forte presença no contexto judicial. Estudando o desenvolvimento da expressão dātu $\check{s} a$ šarri nos documentos babilônicos do período aquemênida, Sophie Démare-Lafont desenvolve uma hipótese de grande interesse. Segundo ela, dātu $\check{s} a \check{s} a r r i$ se referiria originalmente à atividade judicial do rei, suas decisões para casos específicos, provavelmente na forma de "rescritos" reais, orientando os juízes dos tribunais locais. Apenas progressivamente tais normas, oriundas da prática judicial, teriam sido compiladas e mencionadas em contratos entre privados (DÉMARE-LAFONT, 2006).

Démare-Lafont (2006) destaca outro fato importante: na inscrição trilíngue de Behistun, $\S 8$, o termo dāta é traduzido para o acadiano dinātu (plural de dīnu), que tem o sentido de “decisões judiciais" do rei, precisamente a mesma palavra usada para denotar os julgamentos de Hamurabi em suas leis. Assim, parece que o persa antigo dāta também se relacionaria à atividade judicial do $\mathrm{rei}^{18}$.

Há fortes razões para acreditar que o redator de Ester, ao falar das "leis" de persas e medos, estivesse se referindo aos costumes persas e a decisões do rei para casos específicos. Primeiramente porque, como vimos, a principal fonte do direito próximo-oriental era o costume, não havendo uma tradição de códigos orientais que pudesse justificar a noção de um direito escrito generalizado nessas sociedades. Além disso, como vimos, o livro de Ester faz

${ }^{18}$ DÉMARE-LAFONT, 2006, §13. 
Cad. Líng. Lit. Hebr., n. 15, p. 232-249, 2017

uso de um termo emprestado do persa antigo altamente polissêmico, expressando a ordem divina, as regulações fiscais do império, o direito costumeiro ou a atividade judicial do monarca ${ }^{19}$. Em nenhum desses casos há a noção de um direito positivo ou de um conjunto de normas legais escritas.

Essa constatação tem implicações importantes, uma vez que as duas situações em que o autor de Ester menciona a irrevogabilidade das "leis" persas dizem respeito a decisões do rei para casos particulares, em situação análoga à atividade judicial do monarca. A punição de Vasti, por exemplo, não emana de nenhuma norma do direito positivo, mas do costume (vedando certa insubordinação), reforçado por uma sanção real inscrita nas leis e tornada irrevogável. Da mesma forma, como notou Michael Lefebvre, as decisões do rei dirigidas aos judeus (3:1-15 e 8:8) têm natureza de sentenças reais destinadas, inicialmente, a punir os transgressores de normas públicas $(3: 8)^{20}$. Ao contrário de uma "legislação" criativa do rei, voltada à estipulação de regras gerais, as decisões mencionadas em Ester são ad hoc e apenas reiteram o direito costumeiro por meio de condenações.

Mesmo os decretos reais, note-se, constituem gênero muito particular, voltado à regulação de matérias específicas (pagamento de tributos ou liberação de dívidas, por exemplo) com destinatários relativamente mais indeterminados, diferentemente do que se constata em Ester (WELLS, 2005, p. 188). Além disso, ainda que as decisões de Assuero sejam apresentadas formalmente pelo redator de Ester como "decretos", sua natureza condenatória as aproxima muito mais da atividade judicial do monarca.

Que uma decisão judicial da autoridade máxima, uma vez formalizada, fosse imutável ou, em outras palavras, “irrevogável” não é em nada absurdo ou impraticável. Na Antiguidade, essa talvez fosse a expressão incipiente de um princípio de segurança jurídica,

\footnotetext{
${ }^{19}$ A tradução de dāta por nómos na Septuaginta é igualmente plurívoca.

${ }^{20}$ Cf. também LEFEBVRE, 2006, p. 100.
} 
refletida em regras como o ne bis in idem ou a res judicata das sentenças ${ }^{21}$. Além de representar uma ameaça à ideologia monárquica próximo-oriental, a reforma ilimitada de decisões reais para casos particulares significaria uma eterna incerteza quanto à sorte dos súditos, sendo muito razoável que as sentenças e decisões do rei, autoridade máxima no império, fossem, pelo menos em teoria, fixas.

O direito antigo nos fornece numerosos exemplos de tentativas de limitação da possibilidade de reformar sentenças, seja, inicialmente, pela vedação do ajuizamento de ação idêntica contra os mesmos sujeitos (ne bis in idem), seja, mais tarde, pela impossibilidade de apelação ou reforma de decisões judiciais. No antigo Oriente Próximo, as "leis" de Hamurabi indicam que punições severas eram reservadas aos juízes que alteravam um veredito posto por escrito (Hamurabi, §5). Registros de julgamentos mesopotâmicos também demonstram que as partes num litígio se comprometiam, por juramento, a não litigar novamente acerca do mesmo fato, provavelmente a fim de evitar decisões dissonantes (WILCKE, 1998, p. 55).

$\mathrm{Na}$ antiguidade romana, a regra era válida dentro daquilo que seria compreendido pelas modernas categorias de direito civil e criminal. As quaestiones perpetuae do período republicano, por exemplo, eram tribunais de caráter penal que não permitiam apelação dos seus vereditos (ALEXANDER, 2010, p. 242). Mommsen (1991, p. 286) descreve o princípio segundo o qual uma sentença que tivesse sido emitida se dava "uma vez e para sempre" e afirma que esta regra era respeitada durante a República e o Principado. Ao menos para o ne bis in idem, há evidência de sua aceitação no Codex Justinianus ${ }^{22}$.

Evidentemente, a existência de uma regra determinando a imutabilidade de decisões reais não implica sua observância incondicional na vida prática. O direito é categoria deôntica

\footnotetext{
${ }^{21}$ Palavra aqui usada em sentido lato. O termo "sentença" no direito brasileiro denotava o ato que colocava fim ao processo. Com o Código de Processo Civil de 2015 (art. 316), diz-se, a rigor, que a sentença põe fim à fase de conhecimento no processo (ou extingue a execução).

${ }^{22}$ C. IX. 2.9.
} 
Cad. Líng. Lit. Hebr., n. 15, p. 232-249, 2017

que não se identifica imediatamente com a realidade histórica que pretende regrar. Nossas fontes têm muitas referências a imperadores e reis transgressores de normas, inclusive no período aquemênida. O Cambises de Heródoto encontra respaldo em disposição normativa conferindo ao rei poder absoluto para então contornar uma vedação costumeira ${ }^{23}$. Dario I, por exemplo, desfez uma sentença condenatória já durante sua execução ${ }^{24}$. Em Roma, Suetônio narra a tentativa do imperador Vespasiano de reverter a execução de Helvidius Priscus ${ }^{25}$.

Ainda assim, o fato é que poderia haver um princípio de imutabilidade das normas emanadas da autoridade real sem que isso fosse impraticável ou absurdo. Provavelmente, isso era verídico em decisões judiciais emanadas da autoridade real, bem como de decretos ad hoc de caráter condenatório. As decisões do rei para esses casos particulares, é claro, não deviam se confundir com injunções de natureza diversa, os regulamentos fiscais e "administrativos", passíveis de alteração. Além disso, como dissemos, a existência da norma não seria garantia contra violações substanciais. Note-se, por exemplo, que o rei Assuero está justamente transgredindo a regra da "irrevogabilidade" ao neutralizar seu primeiro decreto mediante uma nova decisão, como bem notou Jean Bodin (1579, p. 102, tradução e grifo nosso),

De como todos os éditos são revogáveis: [...] como pode-se ver também no fato de que Dario Mnêmon, a pedido de uma mulher judia, cassou o édito por meio do qual ordenou que a nação judaica fosse exterminada.

Em suma, o estudo das tradições jurídicas do Oriente Próximo indica que seria possível que o redator de Ester tivesse como referência uma regra envolvendo as decisões reais de natureza condenatória, associadas à atividade judicial do rei. Tal princípio não é absurdo ou impraticável, sendo observado em várias sociedades modernas e refletindo uma busca de maior segurança jurídica na aplicação das normas. O livro de Daniel, onde figura a mesma

\footnotetext{
${ }^{23}$ Cf. HERÓDOTO. 3.31.

${ }^{24}$ Cf. HERÓDOTO. 7.194.

${ }^{25}$ Cf. SUETÔNIO, Vida de Vespasiano, 15.1.
} 
noção, é mais problemático, mas deve refletir a mesma realidade histórica. Assim, um fato geralmente invocado como indício do caráter ficto de Ester poderia, em realidade, ser plenamente histórico.

A insistência em debates sobre historicidade é, em certo sentido, curiosa, motivo pelo qual é preciso tecer algumas considerações finais. Discussões dessa natureza já há muito deixaram de ser objeto privilegiado da especulação historiográfica, pois, para numerosos especialistas, afeitos às novidades do pensamento cognominado "pós-moderno", muito mais proveitoso seria examinar os documentos a partir de indagações e instrumentos analíticos diversos, narratológicos, pertinentes a gêneros textuais e às convenções literárias das fontes. Mesmo no ramo dos estudos bíblicos, em que as indagações de natureza "positivista" permanecem populares, as críticas pós-modernas à historiografia não são novidade.

Sem dúvida, tal consciência não implica necessariamente aceitação sem reservas das críticas, sendo legítimas as questões já abordadas. De toda forma, como afirma corretamente Hans Barstad, a consciência de nossas limitações deveria nos conduzir a uma percepção mais aguçada das dificuldades enfrentadas pelos especialistas nesta seara. Barstad (2018) reforça, corretamente, a importância de admitirmos a impossibilidade de responder a perguntas tradicionais de historicidade e fiabilidade histórica diante de evidências disponíveis sem, contudo, negar a possibilidade de se obter algum conhecimento sobre o passado.

Assim, é preciso esclarecer que Ester e Mardoqueu são figuras literárias que podem ou não ter tido correspondentes históricos, havendo, inclusive, aqueles que acreditam que a narrativa de Ester não se pretenderia histórica, mas literária (BERLIN, 2001). Mesmo sendo improvável que a narrativa de Ester reflita a verdade absoluta dos fatos históricos, contudo, é importante termos ciência dos limites enfrentados pelas indagações acadêmicas que jamais poderão ser satisfatoriamente respondidas à luz da informação de que dispomos, sendo 
Cad. Líng. Lit. Hebr., n. 15, p. 232-249, 2017

infrutífero proceder à busca de uma "Ester histórica". Em razão disso, é inaceitável que a mera ausência de informação seja usada como argumento contra a historicidade de qualquer fonte antiga, bíblica ou clássica, e, ademais, é injustificável o tratamento a priori da fonte bíblica como mais anacrônica ou problemática do que outras fontes antigas.

Considerando tais apontamentos e a polêmica que envolve a historicidade dos relatos bíblicos, geralmente alvo de disputas entre religiosos e céticos, o cuidado historiográfico que se impõe é a clara circunscrição do objeto de nossas indagações, de sorte a não extrair conclusões absolutas ou holísticas de tão limitadas observações. Tendo em vista meramente a ambientação histórica da narrativa de Ester, tentamos demonstrar que o problema da irrevogabilidade da lei dos persas e medos, um dos obstáculos contrapostos à defesa da historicidade de Ester, pode, na verdade, convergir para a evidência disponível a respeito da tradição jurídica e administrativa do Oriente Próximo. 
Araujo, Matheus. O Livro de Ester e a Irrevogabilidade das Leis Aquemênidas

\section{Bibliografia}

ALEXANDER, M. C. Law in the Roman Republic. In: ROSENSTEIN, N.; MORSTEINMARX, R. (Eds.). A companion to the Roman Republic. Malden: Wiley-Blackwell, 2010.

ARAUJO, Matheus Treuk Medeiros de. Direito e poder na Pérsia Aquemênida. Revista Poder e Cultura, v. 3. n. 5, p. 16-29, 2016.

BARSTAD, H. M. History and the Hebrew Bible: studies in Ancient Israelite and Ancient Near Eastern historiography. Tübingen: Mohr Siebeck, 2008.

BAUM, H. M. (Ed.). Code of Hammurabi, King of Babylon. Records of the Past. Washington, DC: Records of the Past Exploration Society, 1903. v. 2.

BAZAGLIA, P. Bíblia de Jerusalém. 5. ed. São Paulo: Paulus, 2008.

BERLIN, A. The Book of Esther and Ancient Storytelling. Journal of Biblical Literature, Atlanta, v. 120, n. 1, p. 3-14, 2001.

BODIN, J. Les Six Livres de la Republique. Lyon: Imprimerie de Jean de Tournes, 1579.

BOTTÉRO, J. Mésopotamie. Le "Code" de Hammurabi. In: L'écriture, la raison et les dieux. Paris: Gallimard, 1987.

BOUZON, E. Origem e natureza das coleções do direito cuneiforme. Revista Justiça e História, v. 2, n. 3, p. 22-38, 2002.

BRIANT, P. From Cyrus to Alexander: a history of the Persian Empire. Winona Lake: Eisenbrauns, 2002.

BUCCI, O. L'impero achemenide come ordinamento giuridico sovrannazionale e arta come principio ispiratore di uno "ius commune Persarum" (data). Publicações de l'École Française de Rome, Roma, v. 67, n. 1, p. 89-122, 1983.

DANDAMAEV, M. A.; LUKONIN, V. G. The culture and social institutions of ancient Iran. Cambridge, UK: Cambridge University Press, 2004. 
Cad. Líng. Lit. Hebr., n. 15, p. 232-249, 2017

DÉMARE-LAFONT, S. dātu ša šarri. La "loi du roi” dans la Babylonie achéménide et séleucide. Revue Droit et Cultures, Paris, v. 52, n. 2, p. 13-26, 2006.

FOX, M. V. Character and Ideology in the Book of Esther. 2. ed. Grand Rapids: Eerdmans, 2001.

FREI, P. Persian Imperial Authorization: a summary. In: WATTS, J. W. Persia and Torah: the theory of Imperial Authorization of the Pentateuch. Atlanta: Society of Biblical Literature, 2001.

HERODOTUS. The Persian Wars, v.1 (books I-II). Tradução de Albert Denis Godley. Cambridge (Massachusets), Londres: 1999.

. The Persian Wars, v. 2 (books III-IV). Tradução de Albert Denis Godley. Cambridge (Massachusets), Londres: 1938.

- The Persian Wars, v.3 (books V-VII). Tradução de Albert Denis Godley. Cambridge (Massachusets), Londres: 2006.

. The Persian Wars, v. 4 (books VIII-IX). Tradução de Albert Denis Godley. Cambridge (Massachusets), Londres: 1925.HOLTZ, S. E. Neo-Babylonian Trial Records. Atlanta: Society of Biblical Literature, 2014.

KUHRT, A. The Persian Empire: a corpus of sources from the Achaemenid Period. London: Routledge, 2007.

LECOQ, P. Les inscriptions de la Perse achéménide. Paris: Gallimard, 1997.

LEFEBVRE, M. Collections, Codes and Torah: the re-characterization of Israel's written law. New York: T \& T Clark, 2006. 
ARAujo, Matheus. O Livro de Ester e a Irrevogabilidade das Leis Aquemênidas

LEVENSON, J. D. Esther: a commentary. Louisville: Westminster John Knox Press, 1997.

LLEWELLYN-JONES, L. King and Court in Ancient Persia: 559 to 331 BCE. Edinburgh: Edinburgh University Press, 2013.

MATHESON, S. A. Persia: an archaeological guide. London: Faber and Faber Limited, 1979. MOMMSEN, T. Derecho Penal Romano [Römischen Strafrecht, 1899]. Tradução Pedro Dorado Montero. Bogotá: Editorial Temis, 1991.

MOORE, C. A. Esther (The Anchor Yale Bible commentaries). New York: Doubleday, 1971.

OLMSTEAD, A. T. E. History of the Persian Empire. Chicago: Londres: The University of Chicago Press, 1948.

PATON, L. B. A critical and exegetical commentary on the book of Esther. Edinburgh: T. \& T. Clark, 1908.

SHEA, W. H. Esther and History. Andrews University Seminary Studies, Michigan, v. 14, p. 227-246, 1976.

SLANSKI, K. E. The Law of Hammurabi and Its Audience. Yale Journal of Law \& the Humanities, New Haven, v. 24, n. 1, p. 97-110, 2012.

SUETONIUS. Biographies of the Roman Emperors. Tradução John Carew Rolfe. Cambridge, MA: Harvard University Press, 1914. (Collection Loeb Classical Library).

WELLS, B. Law and Pratice. In: SNELL, Daniel C. (Ed.). A Companion to the ancient Near East. Malden: Oxford: Carlton: Blackwell Publishing, 2005.

WILCKE, C. Care of the Elderly in Mesopotamia in the Third Millennium B.C. In: STOL, M.; VLEEMING, S. P. (Eds.). The Care of the Elderly in the Ancient Near East. New York: Elmer Holmes Bobst, 1998.

YAMAUCHI, E. M. Persia and the Bible. Michigan: Baker Books, 1996. 